\title{
Combined Effects of Intrinsic Facilitation and Modulatory Inhibition of Identified Interneurons in the Siphon Withdrawal Circuitry of Aplysia
}

\author{
Adam S. Bristol, ${ }^{1}$ Thomas M. Fischer, ${ }^{2}$ and Thomas J. Carew ${ }^{3}$ \\ ${ }^{1}$ Department of Psychology, Yale University, New Haven, Connecticut 06520-8205, 2Department of Psychology, Wayne \\ State University, Detroit, Michigan 48202, and '3epartment of Neurobiology and Behavior, University of California, Irvine, \\ Irvine, California 92697-4550
}

Synaptic plasticity can be induced through mechanisms intrinsic to a synapse or through extrinsic modulatory mechanisms. In this study, we investigated the relationship between these two forms of plasticity at the excitatory synapse between L29 interneurons and siphon motor neurons (MNs) in Aplysia. Using isolated ganglia, we confirmed that the L29-MN synapses exhibit a form of intrinsic facilitation: post-tetanic potentiation (PTP). We also found that L29-MN synapses are modulated by exogenous application of 5-HT: they are depressed after 5-HT exposure. We next investigated the functional relationship between an intrinsic facilitatory process (PTP) and extrinsic inhibitory modulation (5-HT-induced depression). First, we found that application of 5-HT just before L29 activation results in a reduction of PTP. Second, using semi-intact preparations, we found that tail shock (TS) mimics the effect of 5-HT by both depressing L29 synaptic transmission and by reducing $\mathrm{L} 29$
PTP. Third, we observed a significant correlation between L29 activity during TS and subsequent synaptic change: lowresponding L29s showed synaptic depression after TS, whereas high-responding L29s showed synaptic facilitation. Finally, we found that we could directly manipulate the sign and magnitude of TS-induced synaptic plasticity by controlling L29 activity during TS. Collectively, our results show that the L29-MN synapses exhibit intrinsic facilitation and extrinsic modulation and that the sign and magnitude of L29-MN plasticity induced by TS is governed by the combined effects of these two processes. This circuit architecture, which combines network inhibition with cell-specific facilitation, can enhance the signal value of a specific stimulus within a neural network.

Key words: information processing; neural network; posttetanic potentiation; serotonin; synaptic plasticity; withdrawal reflex
Synaptic plasticity is fundamental to neural processing. Essential elements of synaptic plasticity can be captured by three features: mechanism, sign, and time scale. In considering mechanism, plasticity can arise from cellular events either intrinsic or extrinsic to a synapse (Krasne, 1978). For example, intrinsic properties of a synapse allow the expression of different forms of plasticity associated with different rates of presynaptic activity. In contrast, plasticity may be induced by the activation of modulatory cells or circuits extrinsic to a synapse. In considering the sign of plasticity, synaptic change can reflect either the facilitation or inhibition of transmission. Thus, there are facilitatory forms of intrinsic plasticity, such as post-tetanic potentiation (PTP; Zucker, 1989; Fisher et al., 1997), as well as inhibitory forms, such as homosynaptic depression (Armitage and Siegelbaum, 1998; Bear, 1999). Similarly, extrinsic modulation can be facilitatory (e.g., heterosynaptic facilitation; Castellucci and Kandel, 1976; Emptage and Carew, 1993; Katz and Frost, 1995) or inhibitory (e.g., presynaptic inhibition; Ryall, 1978; Montarolo et al., 1988). Finally, different forms of synaptic plasticity are manifest over different temporal domains. Some forms last from seconds to

Received June 4, 2001; revised Aug. 27, 2001; accepted Aug. 29, 2001.

This work was supported by National Institute of Mental Health Grant MH41083 to T.J.C. We thank Stephane Marinesco, Angela Purcell, Carolyn Sherff, and Michael Sutton for helpful discussions.

Correspondence should be addressed to Thomas J. Carew, Department of Neurobiology and Behavior, University of California, Irvine, Irvine, CA 92697-4550. E-mail: tcarew@uci.edu.

Copyright (C) 2001 Society for Neuroscience $\quad 0270-6474 / 01 / 218990-11 \$ 15.00 / 0$ minutes (e.g., PTP), whereas others persist for hours and days [e.g., long-term potentiation (LTP)] (for review, see Malenka and Nicoll, 1999). If different forms of plasticity share overlapping temporal domains, then intrinsic and extrinsic forms of plasticity can interact. For example, hippocampal LTP is disrupted by extrinsic corticosteroids (Kim and Yoon, 1998), endogenous opioids (Terman et al., 1994), or serotonergic modulation (5-HT; Corradetti et al., 1992; Villani and Johnston, 1993). Mechanistically, when intrinsic and extrinsic plasticities occur in parallel, the result may be attributable to an interaction between the underlying mechanisms (Hawkins et al., 1983; Walters and Byrne, 1983) or a summation of independent mechanisms (Buonomano and Merzenich, 1998).

The siphon withdrawal reflex (SWR) in Aplysia allows the examination of the functional significance of synaptic plasticity in a behaviorally relevant neural circuit. One class of interneurons in the SWR circuit, the L29s (approximately five in number; Hawkins et al., 1981a), provides a major source of excitation to siphon motor neurons (MNs), and this synapse exhibits PTP, a form of facilitatory intrinsic plasticity (Hawkins et al., 1981a; Fischer and Carew, 1995; Frost and Kandel, 1995). Tail shock (TS) enhances the SWR and is thought to evoke the release of extrinsic modulators, including 5-HT, in the SWR circuit (Hawkins, 1989; Mackey et al., 1989; Fischer et al., 1997) (see Marinesco and Carew, 2000 for TS-elicited 5-HT release in the tail withdrawal circuit). TS activates some L29s more effectively than others, presumably because of differing receptive fields (Hawkins and Schacher, 1989), allowing the examination of the 
combined effects of extrinsic and intrinsic plasticity at an identified synapse.

Here we report that L29-MN synapses are depressed immediately after exposure to 5-HT and that 5-HT-induced depression reduces the effectiveness with which L29s drive follower MNs. By reducing baseline synaptic transmission, 5-HT also reduces the magnitude of L29-MN PTP. TS mimics the effects of 5-HT by depressing both synaptic transmission and intrinsic plasticity in the L29s. When we examined the relationship between L29 responsiveness to TS and subsequent change in the synaptic strength, we found a significant positive correlation: lowresponding L29s showed synaptic depression after TS, whereas high-responding L29s showed synaptic facilitation. Finally, we found that the magnitude and sign of L29-MN synaptic plasticity could be controlled by manipulating L29 activity during TS. Collectively, these results show that intrinsic facilitation and extrinsic modulation of the L29-MN synapse co-occur after TS. They further show that the ultimate sign of plasticity at this synapse is governed by the summation of these two processes. This functional architecture, in turn, produces a form of "centersurround" processing at the interneuronal level of the SWR circuitry: intrinsic facilitation induced by high responding of L29s is superimposed on a modulatory background of general inhibition, thus providing enhanced contrast for information processing within the network.

Some of these results have been reported previously in abstract form (Bristol et al., 1998, 1999).

\section{MATERIALS AND METHODS}

Adult Aplysia californica (100-300 gm) were acquired commercially (Marinus, Long Beach, CA; Marine Specimens Unlimited. Long Beach, CA; Aplysia Resource Center, Coral Gables, FL) and housed individually in a 6001 aquarium with continuously circulating artificial seawater (Instant Ocean, Aquarium Systems, Mentor, OH) at $\sim 15^{\circ}$ C. Animals were fed dried seaweed twice weekly.

Experimental preparations. Animals were anesthetized with an injection of isotonic $\mathrm{MgCl}_{2}$ into the body cavity. All peripheral nerves were cut except the P9 nerves, which innervate the tail. The CNS (abdominal ganglion and ring ganglia) and the tail were then excised from the animal and transferred to a recording dish coated with silicone elastomer (Sylgard; Dow-Corning, Midland, MI). The abdominal ganglion was briefly fixed (40 sec immersion in $0.04 \%$ gluteraldehyde) to facilitate desheathing and to prevent contractions of the connective tissue. The recording dish was fitted with two separate chambers: one contained the CNS, and the other contained the tail. The P9 nerves were passed between the chambers via a small open slit in the separating barrier. The slit was then sealed using petroleum jelly to improve electrical isolation and to allow for independent manipulation of bath levels. The tail was cannulated and continuously perfused with artificial seawater (ASW; in mM: $460 \mathrm{NaCl}$, $55 \mathrm{MgCl}_{2}, 11 \mathrm{CaCl}_{2}, 10 \mathrm{KCl}$, and 10 Trisma, $\mathrm{pH} \mathrm{7.6)} \mathrm{throughout} \mathrm{the}$ experiment. In some experiments, (isolated ganglion), an abdominal ganglion was removed, briefly fixed, and then pinned ventral side up in a $2 \mathrm{ml}$ volume Petri dish coated with a thin layer of silicone elastomer.

In all preparations, the left abdominal hemiganglion was desheathed in a 1:1 mixture of ASW and isotonic $\mathrm{MgCl}_{2}$ to prevent synaptic transmission. Throughout the experiment, ganglia were continuously perfused with ASW at room temperature $\left(20^{\circ} \mathrm{C}\right)$ at $\sim 2 \mathrm{ml} / \mathrm{min}$ (isolated ganglion preparations) or $6 \mathrm{ml} / \mathrm{min}$ (semi-intact preparations) and illuminated from below through a dark-field condenser. The perfusion system also delivered bath applications of 10 or $50 \mu \mathrm{M} 5$-HT in ASW.

Intracellular recordings. Ganglia were visualized with a Zeiss dissecting microscope fitted with a recording stage. Standard intracellular recording techniques were used. Neurons were impaled with glass microelectrodes (resistance 6-15 $\mathrm{M} \Omega$ ) filled with $3 \mathrm{M} \mathrm{KCl}$. Electrical potentials were amplified on a Getting 5-A amplifier (Getting Instruments, IA City, IA) and then digitized (Medical Systems Corp., Greenvale, NY) for tape storage and computer analysis. Data analysis was conducted using AXOSCOPE data acquisition software (Axon Instruments, Foster City, CA) and the POWERLAB data acquisition unit (ADInstruments, Milford, MA) and accompanying Chart 3.6 software.

Individual L29 interneurons were identified on the basis of their size, position, action potential, and by their characteristic "stuttering" response to depolarizing pulses or cutaneous stimulation (Hawkins et al., 1981a; Fischer and Carew, 1995; Frost and Kandel, 1995). Siphon MNs were identified by their size, location, and by their tonic firing activity (Hickie and Walters, 1995; Belkin and Abrams, 1998). For the duration of the experiment, MNs were hyperpolarized to $-70 \mathrm{mV}$ to prevent spiking.

Experimental procedures. Tests of L29-MN synaptic strength (EPSP tests) were conducted by measuring the peak voltage of the MN EPSP generated by a single spike in the L29 (2-6 nA; $20-50 \mathrm{msec})$. In some experiments, the area under the complex EPSP in the MN (expressed as millivolts $\cdot$ second) was integrated to provide a quantitative measure of the efficacy with which the L29 activated the MN during a tetanus. PTP tests were used to measure intrinsic enhancement of the L29-MN EPSP after tetanus. A PTP test consisted of: (1) a baseline EPSP test, followed $1 \mathrm{sec}$ later by (2) intracellular activation of an L29 at $20 \mathrm{~Hz}$ for $5 \mathrm{sec}$ (current pulses $20 \mathrm{msec}$ at 1.5 times the intensity to elicit a single action potential to ensure firing over the course of the tetanus; intensity range, 5-9 nA), and (3) EPSP tests conducted every $10 \mathrm{sec}$ for $1 \mathrm{~min}$ immediately after the tetanus, with an additional EPSP test taken at 5 min after tetanus.

In experiments examining the effects of 5-HT on L29 synaptic transmission, two baseline EPSP tests were taken 5 min intertrial interval (ITI)] followed $3 \mathrm{~min}$ later by a $2 \mathrm{~min}$ perfusion of 5-HT. Three post-5-HT EPSP tests were taken at a 5 min ITI starting $\sim 30 \mathrm{sec}$ after 5-HT. In experiments examining the effects of 5-HT on L29-MN PTP, multiple PTP tests were conducted in the same preparation: (1) before 5-HT perfusion, (2) $30 \mathrm{sec}$ after 5-HT, and/or (3) $10 \mathrm{~min}$ after 5-HT (see Fig. 5).

In some experiments using TS, a PTP test was administered before TS to insure that the synapse under study was capable of exhibiting intrinsic enhancement. Four experiments (7\% of cases) were discarded for failing to show enhancement $10 \mathrm{sec}$ after tetanization. In the remaining experiments, the tetanus was $1 \mathrm{sec}$ in duration to match the duration of TS. An additional EPSP test was administered 5 min after the initial PTP test to serve as a baseline measure for the first TS. Immediately after this EPSP test, a $1 \mathrm{sec}$ TS was administered and the amplitude of the L29-MN synapse was measured at $10 \mathrm{sec}$ intervals for $1 \mathrm{~min}$ and again at $5 \mathrm{~min}$ after shock. In these experiments, the L29 was hyperpolarized during the second TS if it fired $>10$ spikes during the first TS (tail-responsive L29). Conversely, it was activated during the second TS if it fired fewer than 10 spikes during the first TS (tail-unresponsive L29). L29 activity during TS was manipulated by either passing constant hyperpolarizing current (5-9 $\mathrm{nA}$ ) or by activating the cell at $20 \mathrm{~Hz}$ for the duration of the TS. Tail shocks $(45-60 \mathrm{~mA}, 1 \mathrm{sec})$ were delivered to the dorsal surface of the tail using a bipolar electrode. The electrode covered a surface area of $\sim 2$ $\mathrm{cm}^{2}$ and was lowered onto the tail immediately before the shock and retracted from the tail immediately after shock.

Statistical analysis. All summary data are presented graphically as means \pm SEM. $N$ values indicate number of preparations. Repeatedmeasures ANOVA, paired $t$ tests, and linear contrasts (a focused test of the difference between the mean of one condition with the combined means of several conditions) were used as tests for differences between means (Howell, 1997). An $\alpha$ level of 0.05 was adopted for all tests of statistical significance.

\section{RESULTS}

\section{Intrinsic facilitation of L29: PTP}

Intrinsic enhancement (PTP) at the L29-MN synapse has been demonstrated previously (Frost et al., 1988). Confirming this observation, as shown in Figure 1, we found that intracellular activation of the L29 at $20 \mathrm{~Hz}$ for $5 \mathrm{sec}$ led to a significant enhancement of synaptic transmission that was greatest at the first test $10 \mathrm{sec}$ after tetanus $(\sim 250 \%$ enhancement; mean difference between baseline test and $10 \mathrm{sec}$ after test $=9.34 \mathrm{mV} ; t_{(34)}=5.59$; $p<0.01)$. Synaptic strength was still significantly elevated above baseline when tested 5 min after tetanus (mean difference $=2.46$ $\left.\mathrm{mV} ; t_{(11)}=2.95 ; p<0.01\right)$ but returned to baseline at $10 \mathrm{~min}$ after tetanus (mean difference $=1.35 \mathrm{mV} ; t_{(12)}=1.94$; NS). The time 

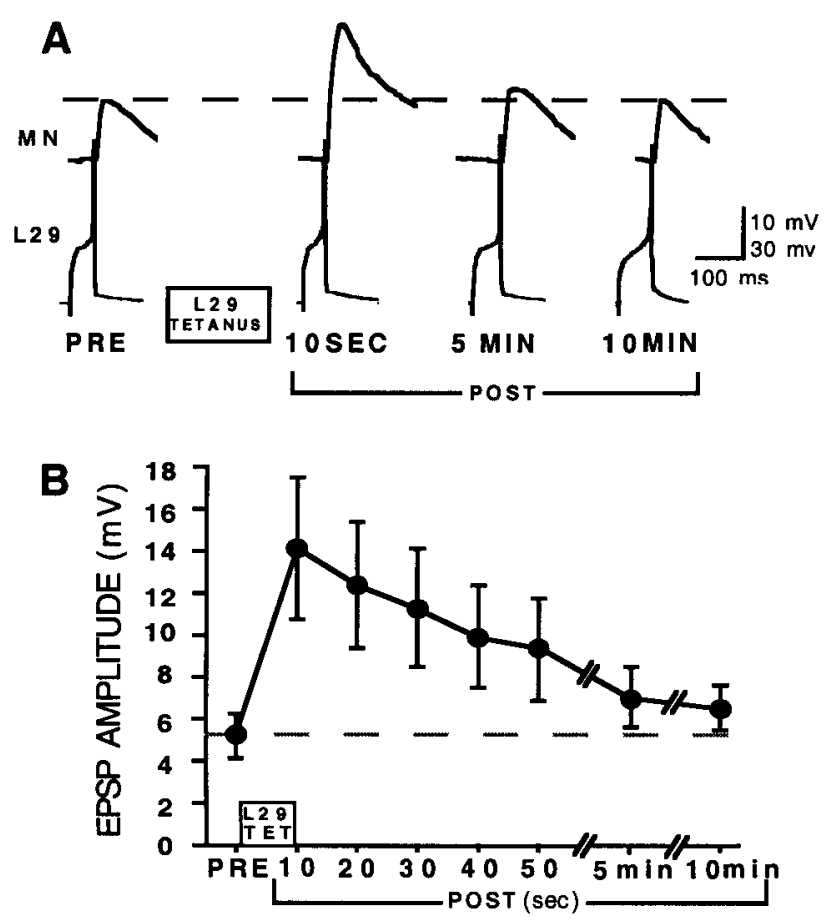

Figure 1. Post-tetanic potentiation (PTP) of the L29-MN synapse after intracellular activation. After measuring the baseline EPSP amplitude, L29 was activated intracellularly at $20 \mathrm{~Hz}$ for $5 \mathrm{sec}$. A, Simultaneous intracellular recordings from a siphon $\mathrm{MN}$ and an L29 interneuron. Tetanus symbol indicates L29 activation. B, Summary data from synapses both before and after tetanus $(N=35)$. Synaptic enhancement was greatest when measured $10 \mathrm{sec}$ after activation.

course of L29-MN synaptic enhancement after tetanus is consistent with previous reports (Frost et al., 1988; Frost and Kandel, 1995). Our data, taken with previous reports, show that the L29 synapse exhibits a robust form of intrinsic enhancement, PTP.

\section{Extrinsic modulation of L29: 5-HT-induced synaptic depression}

5-HT modulates synaptic transmission at several sites in the SWR circuit (Frost et al., 1988; Trudeau and Castellucci, 1993). Therefore, we asked whether exposure to 5-HT would have a modulatory effect on the L29-MN synapse. We tested two concentrations of 5-HT (10 and $50 \mu \mathrm{M})$, both of which had qualitatively similar effects. An example using $50 \mu \mathrm{M}$ is shown in Figure $2 A$. Summary data (shown in Fig. $2 B$ ) revealed that a brief, 2 min exposure to 5-HT led to a transient depression of the L29-MN EPSP that was greatest when tested immediately after 5-HT perfusion (mean reduction after $10 \mu \mathrm{M}=74 \%$; $t_{(8)}=12.87, p<$ 0.05 ; after $50 \mu \mathrm{M} 5$-HT $\left.=80 \% ; t_{(6)}=12.27, p<0.05\right)$. EPSP tests at 5 and $10 \mathrm{~min}$ after 5 -HT washout revealed a gradual recovery, although the EPSP was still modestly (and significantly) reduced at the $10 \mathrm{~min}$ test (mean reduction after $10 \mu \mathrm{M}=26 \%$; $t_{(5)}=$ $10.13, p<0.05$; after $50 \mu \mathrm{M} 5$-HT $=46 \%$; $\left.t_{(5)}=3.49, p<0.05\right)$. These data are consistent with previous results by Trudeau and Castellucci (1993) who found that 5-HT depressed synaptic transmission from various unidentified excitatory interneurons in the abdominal ganglion.

To examine whether changes in presynaptic or postsynaptic input resistance may contribute to the 5-HT-induced modulation of the L29-MN EPSP, we injected pulses of hyperpolarizing current into the L29 and MN before each EPSP test. Similar to results obtained by Frost et al. (1988), we found that 5-HT
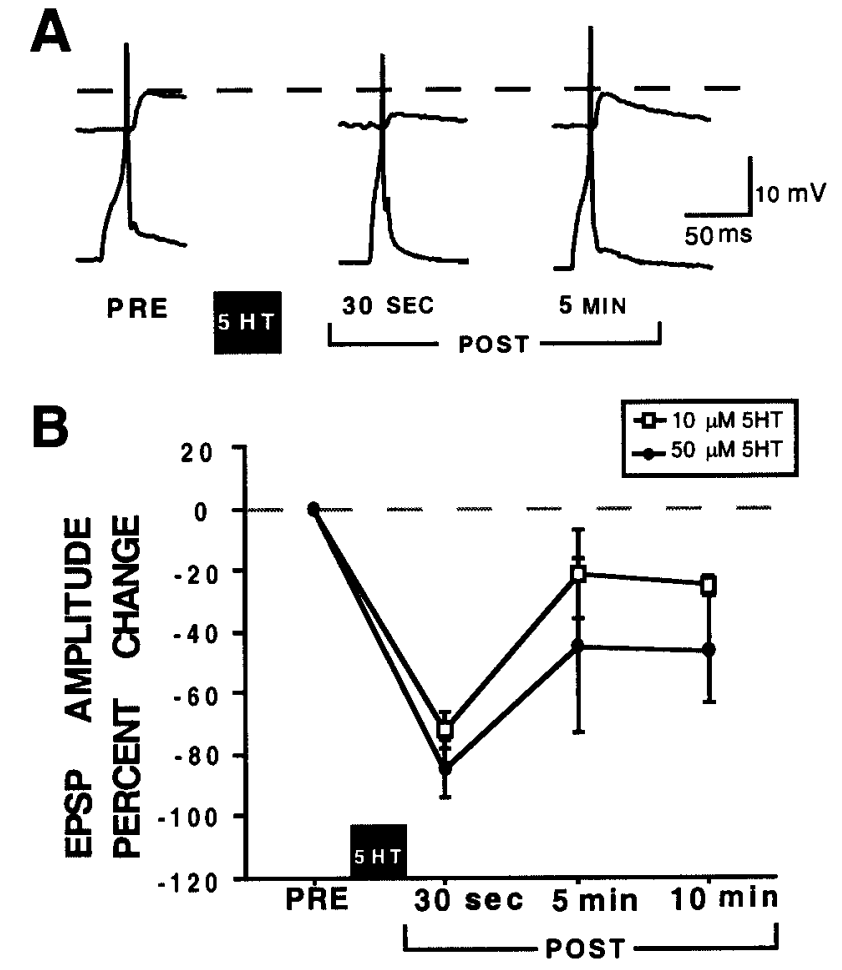

Figure 2. 5-HT transiently inhibits the L29-MN EPSP. After measuring the baseline EPSP amplitude, 5-HT (10 or $50 \mu \mathrm{M})$ was bath-applied for 2 min. $A$, Simultaneous intracellular recordings from a siphon $\mathrm{MN}$ and an L29 interneuron. The 5-HT symbol indicates 5-HT application. 5-HT induced inhibition of the EPSP at the $30 \mathrm{sec}$ test. At 5 min after 5-HT, the EPSP returned to near pre-5-HT levels (dashed lines). B, Summary data from synapses measured both pre-5-HT and post-5-HT $(10 \mu \mathrm{M}, N=9$, mean $=4.08 \mathrm{mV} ; 50 \mu \mathrm{M}, N=7$, mean $=9.78 \mathrm{mV}$ ). In all cases, the magnitude of 5-HT-induced inhibition was greatest $30 \mathrm{sec}$ after 5-HT.

reduced L29 input resistance (Fig. 3) (mean reduction $30 \mathrm{sec}$ after $\left.5-\mathrm{HT}=-1.97 \mathrm{M} \Omega ; t_{(11)}=2.35, p<0.05\right)$. Consistent with the decrease in L29 input resistance, we found that more current was required to elicit a single $\mathrm{L} 29$ spike after 5-HT exposure. In addition, 5-HT reduced MN input resistance (Fig. 3) (mean change $30 \mathrm{sec}$ after 5 -HT $\left.=-5.90 \mathrm{M} \Omega ; t_{(5)}=4.70, p<0.05\right)$. We also noted, as did Frost et al. (1988), that 5-HT triggered a slow hyperpolarization of L29 and a slow depolarization of the MN. One possible interpretation of these results is that 5-HT activates a persistent conductance in L29 that partially shunts the action potential, thereby reducing transmitter release. The reduction in $\mathrm{MN}$ input resistance could also contribute to synaptic depression, but temporal dissociation between recovery in synaptic transmission and MN input resistance suggests a predominately presynaptic mechanism. However, further experiments are necessary to determine the relative contributions of presynaptic and postsynaptic mechanisms to 5-HT-induced depression at this synapse.

We reasoned that if 5-HT reduced the L29-MN EPSP, then after 5-HT exposure, L29 should be less effective in driving the $\mathrm{MN}$ during prolonged synaptic activation. To examine this question, we measured the area under the complex EPSP in the MN recorded during the tetanus of L29 (1) before 5-HT, (2) $30 \mathrm{sec}$ after 5-HT, and (3) $10 \mathrm{~min}$ after 5-HT. Our results are shown in Figure 4. We found that tetanization of L29 administered $30 \mathrm{sec}$ after 5-HT resulted in a significantly reduced complex EPSP in the $\mathrm{MN}$ relative to baseline (mean difference $=25.42 \mathrm{mV} \cdot \mathrm{sec} ; t_{(5)}=$ 4.54; $p<0.01$ ). The complex EPSP measured during the tetanus 


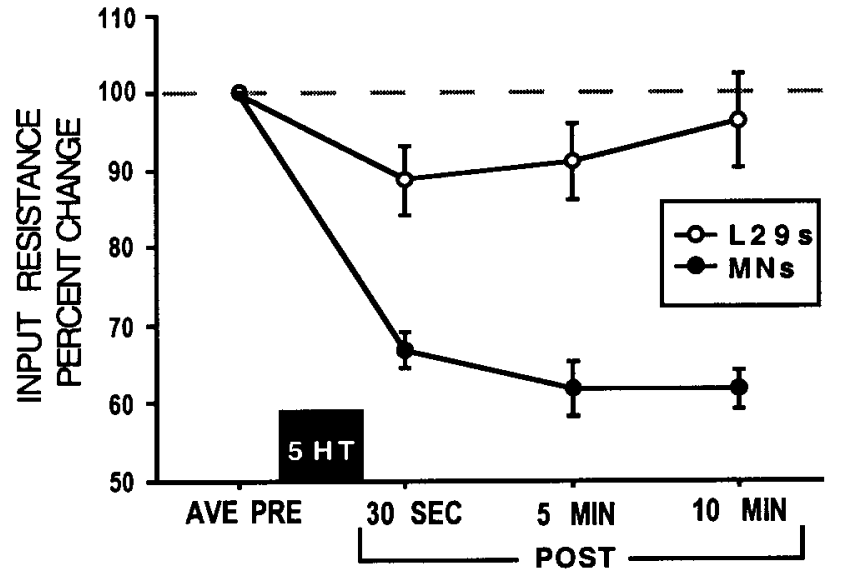

Figure 3. 5-HT reduces L29 and MN input resistance. L29 sec and MNs were injected with $1 \mathrm{nA}$ of hyperpolarizing current before and after 5-HT application. Summary data from 12 experiments examining L29 input resistance (open circles; mean $=25.02 \mathrm{M} \Omega$ ). The 5-HT-induced reduction in L29 input resistance was greatest $30 \mathrm{sec}$ after 5-HT (10 $\mu \mathrm{M})$. Summary data from six experiments examining MN input resistance ( filled circles; mean $=18.13 \mathrm{M} \Omega)$. 5-HT exposure $(50 \mu \mathrm{M})$ reduced $\mathrm{MN}$ input resistance through the 10 min test.

administered 10 min after 5-HT application did not differ from pre-5-HT levels (mean difference $=3.96 \mathrm{mV} \cdot \mathrm{sec} ; t_{(12)}=0.55$; NS). These data show that the effectiveness of the L29-MN synapse can be significantly reduced by 5 -HT exposure.

\section{Combined effects of intrinsic facilitation and extrinsic modulation: 5-HT reduces the magnitude of L29 PTP}

Having established that direct activation of L29 induces synaptic facilitation and that 5-HT exposure induces synaptic depression, we next examined whether these processes could interact by determining whether L29 retained its capacity for PTP during 5-HT modulation. Two types of experiments were conducted to address this question. In the first experiment, L29 was tetanized twice: once before 5-HT exposure and again either $30 \mathrm{sec}$ or 10 min after 5-HT washout. These time intervals were determined by the results of our earlier experiments showing that the maximal effect of 5-HT on the EPSP occurred at $30 \mathrm{sec}$ after treatment, with recovery after $10 \mathrm{~min}$ washout (Fig. 2). As before, 5-HT exposure attenuated the L29-MN EPSP (compare preEPSPs before and after 5-HT). Activation of L29 $30 \mathrm{sec}$ after 5-HT application resulted in significantly less PTP measured 10 sec after tetanus than did activation administered before 5-HT (Fig. $\left.5 A_{1}\right)\left(t_{(6)}=12.48 ; p<0.05\right)$. In contrast, PTP induced 10 min after 5-HT exposure did not differ from pre-5-HT levels (Fig. $\left.5 B_{1}\right)\left(t_{(6)}=0.41 ; \mathrm{NS}\right)$.

Because 5-HT depresses the baseline EPSP, the reduction in L29 PTP could simply reflect a scaling down of PTP to the reduced baseline. Alternatively, the reduction in PTP could be attributable to 5-HT affecting the processes underlying PTP. 5-HT-induced "metaplasticity," where 5-HT modifies the ability of a synapse to undergo plasticity, has previously been described at other synapses in Aplysia (Fischer et al., 1997). To distinguish between these two alternatives, we normalized the data to control for the change in baseline that occurred at the second PTP test. If 5-HT simply scaled down PTP by reducing the initial baseline, then the normalized data for the three PTP tests should overlap. In contrast, if 5-HT were affecting the PTP process, then normalizing the data should still reveal a reduction at the second
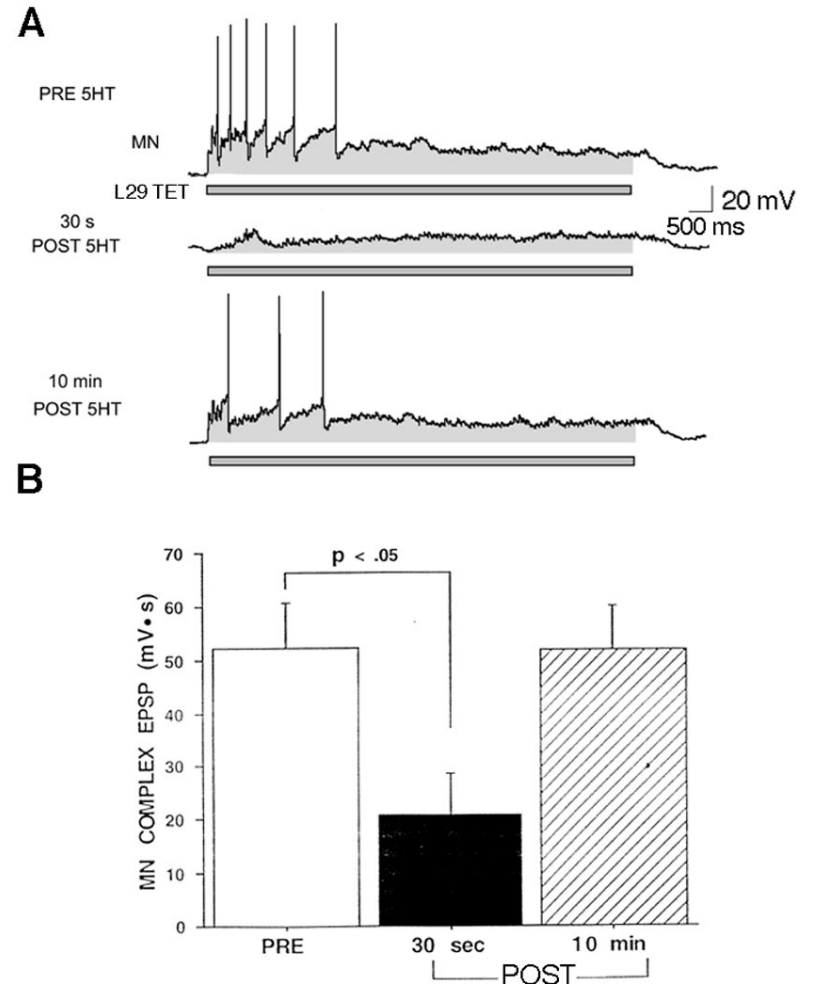

Figure 4. 5-HT transiently reduces the effectiveness of L29 to activate the MN during tetanus. L29 $\mathrm{sec}$ were activated $(20 \mathrm{~Hz}, 5 \mathrm{sec})$ before 50 $\mu \mathrm{M}$ 5-HT, $30 \mathrm{sec}$ after 5-HT, and $10 \mathrm{~min}$ after 5-HT. For each tetanus, the area under the MN complex EPSP recorded during the $5 \mathrm{sec}$ L29 activation was integrated (data expressed as millivolts per second). A, Intracellular recordings from a siphon MN during a single experiment. Shaded area represents period of L29 activation during which the complex EPSP was integrated. In most experiments, MN spiking did not occur during L29 tetanus (see Results). B, Summary data from 15 experiments. A significant difference was observed for MN complex EPSPs measured before and $30 \mathrm{sec}$ after 5-HT. MN complex EPSPs measured 10 min after 5-HT did not differ from pre-5-HT values.

PTP test. We found that when the data were expressed as the percentage change from pre-tetanus baseline, there was no significant difference in the magnitude of PTP when tested either 30 $\sec \left(\right.$ Fig. $\left.5 A_{2}\right)\left(t_{(6)}=0.96\right.$; NS) or $10 \mathrm{~min}\left(\right.$ Fig. $\left.5 B_{2}\right)\left(t_{(6)}=1.03\right.$; $\mathrm{NS})$ after 5 -HT, suggesting that the processes underlying PTP are intact, yet scaled down by 5 -HT-induced inhibition.

To investigate the recovery of PTP from 5-HT-induced inhibition, we conducted additional experiments in which the L29 was tetanized three times: once before 5-HT exposure, again $30 \mathrm{sec}$ after 5-HT, and a third time $10 \mathrm{~min}$ after 5-HT. Similar to the previous experiments, there was a significant difference between the amount of PTP induced by the three test tetani $\left(F_{(2,8)}=6.24\right.$; $p<0.05$; data not shown). A linear contrast (see Materials and Methods) indicated that the amount of PTP induced $30 \mathrm{sec}$ after 5-HT was significantly less than the PTP induced before and 10 min after 5 -HT $\left(F_{(1,8)}=11.13 ; p=0.01\right)$. However, we found that when the data were expressed as the percentage change from pre-tetanus baseline, there was no difference in PTP induced in all three tests $\left(F_{(2,8)}=1.27 ; p=1.27\right.$; data not shown). Collectively, these experiments show that 5-HT reduces the effectiveness of L29 PTP and that this form of plasticity is transient, recovering $\sim 10 \mathrm{~min}$ after washout. These results also suggest that the process of PTP is not affected by 5-HT. Rather, it appears that the reduction in the magnitude of PTP induced by 5-HT is 

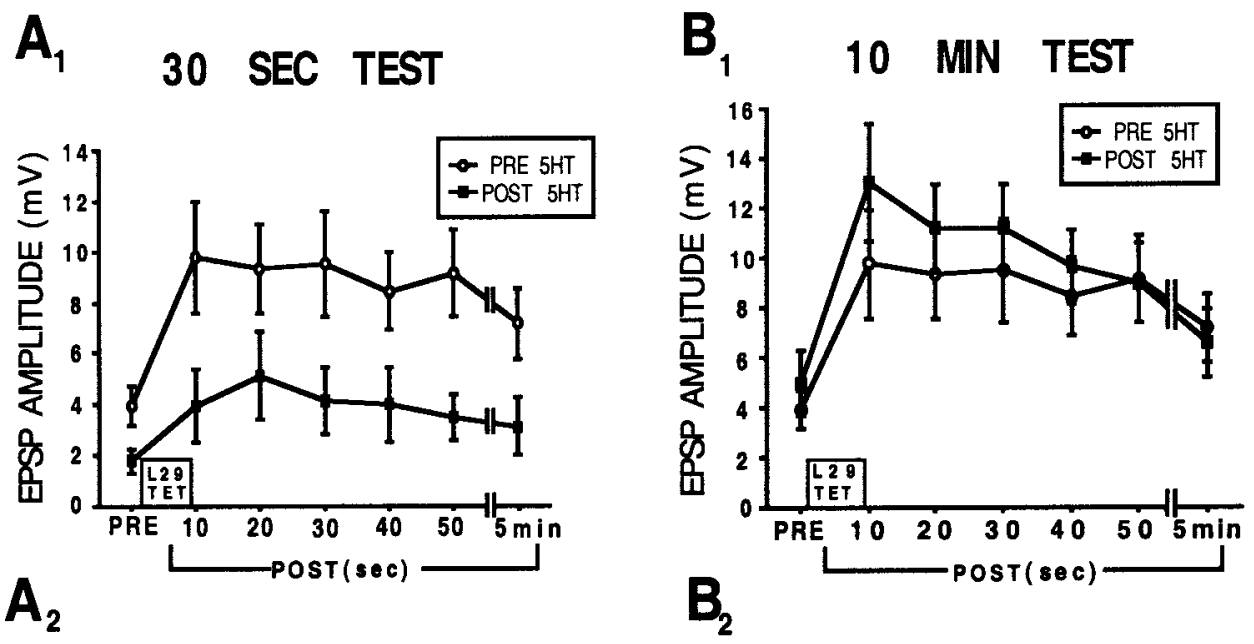

Figure 5. Recovery of L29 PTP from 5-HT-induced inhibition after $10 \mathrm{~min}$ washout. After a pretest of the EPSP, PTP was induced by activating L29 at 20 $\mathrm{Hz}$ for 5 sec. Post-tests of synaptic strength were taken at a $10 \mathrm{sec}$ ITI for up to $1 \mathrm{~min}$, with an additional test at $5 \mathrm{~min}$. This constituted a PTP test (see Materials and Methods). 5-HT $(50 \mu \mathrm{M})$ was perfused for $2 \mathrm{~min}$. 5-HT exposure $(50 \mu \mathrm{M})$ reduced PTP when the second tetanus was administered $30 \mathrm{sec}$ after 5-HT $(N=$ 7) but not when administered $10 \mathrm{~min}$ after 5-HT $(N=12) \cdot A_{1}$, Summary data of 30 SEC TEST. $A_{2}$, Summary data shown in $A_{1}$ expressed as percentage of change from pre-tetanus baseline EPSP. Analysis of percentage of change at $10 \mathrm{sec}$ after tetanus revealed no difference between PTP tests. Note the reduced EPSP amplitude of the post-5-HT PRE value in the 30 sec test reflecting 5-HT-induced inhibition. $B_{1}$, Summary data of 10 MIN TEST. $B_{2}$, Summary data from $B_{1}$ expressed as percentage of change from pre-tetanus baseline EPSP. Analysis of percentage of change at $10 \mathrm{sec}$ revealed that PTP induced $10 \mathrm{~min}$ after 5-HT was no different from pre-5-HT PTP.
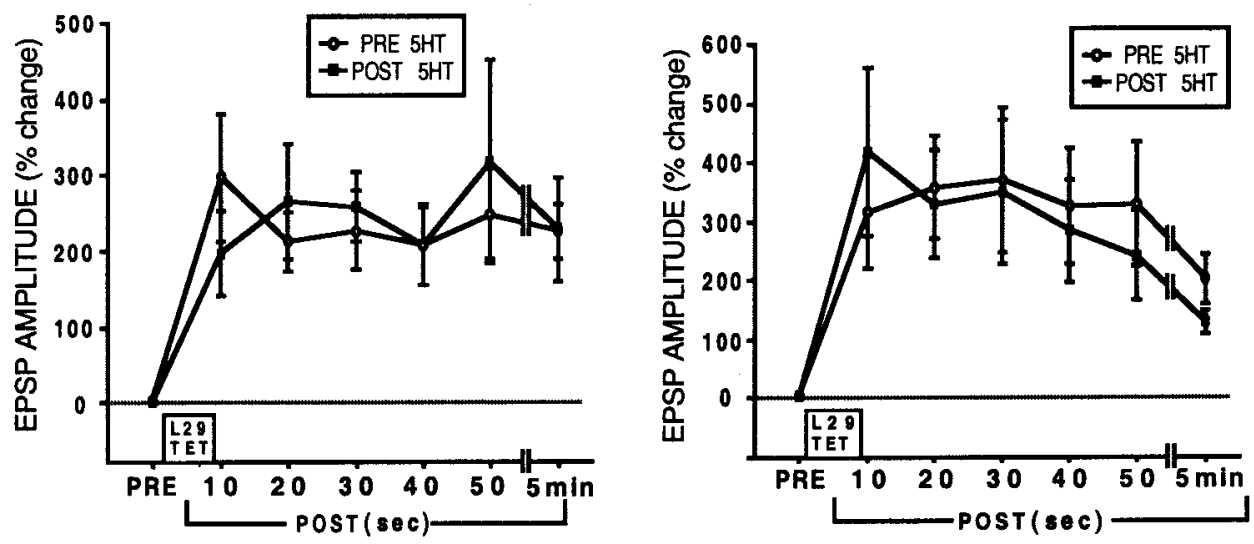

attributable in large part to the effects of 5-HT on baseline synaptic transmission from L29 to the MN. In this manner, the magnitude of the potentiated synaptic input to the MN is transiently and significantly reduced after 5-HT exposure.

\section{Combined effects of intrinsic facilitation and extrinsic modulation: tail shock mimics 5-HT-induced inhibition of L29 PTP}

Many studies of learning in Aplysia have used TS as a reinforcing stimulus (Carew et al., 1981; Marcus et al., 1988; Hawkins et al., 1998). The modulatory effects of TS observed at the synaptic level can often be mimicked by 5-HT (for review, see Byrne and Kandel, 1996). Serotonergic projections have been observed within the abdominal ganglion (Kistler et al., 1985; Longley and Longley, 1986) and in the vicinity of L29 processes (Hawkins, 1989). Moreover, TS has been shown to be capable of activating serotonergic neurons that extend processes into the abdominal ganglion (Mackey et al., 1989). To determine whether TS was capable of mimicking 5-HT-induced inhibition (Fig. 2), we used a preparation consisting of the intact tail connected to the CNS (see Materials and Methods). This preparation allowed us to address three interrelated questions: (1) does TS induce inhibition of the L29-MN EPSP? (2) How do TS and L29 activation interact? (3) Can plasticity at the L29-MN synapse be altered by controlling L29 activity during TS? Briefly, the L29s were first activated using intracellular current injection and then, after recovery of PTP, activated by successive TSs. During the second TS, L29 activation was controlled experimentally (see Materials and Methods). The results of these experiments are shown in Figures 6-10.

First, we asked whether TS depresses the L29-MN synapse. We found that the L29-MN EPSP was significantly reduced $10 \mathrm{~min}$ after the first TS (Fig. 6B) (mean reduction at 10 min after shock $=$ $\left.25 \% ; t_{(28)}=2.52 ; p<0.05\right)$, indicating that TS, like $5-\mathrm{HT}$, is capable of inhibiting this synapse. Preparations not receiving TS showed no change in L29-MN EPSP amplitude over a comparable time period $\left(F_{(2,18)}=0.676 ; \mathrm{NS}\right)$. These results provide evidence for an inhibitory effect of TS on the L29-MN synapse.

Although both TS and 5-HT induce inhibition of the L29-MN synapse, the temporal dynamics of TS-induced inhibition of L29 (Fig. 6) do not directly correspond with 5-HT-induced inhibition (Fig. 2). For example, depression was observed immediately after 5-HT, but showed a more gradual onset after TS (Fig. 7B) (for data collected $10 \mathrm{sec}$ after first TS; mean change, $+138 \%$ ). An important difference between the two types of experiments is that TS induces activation of the L29s, whereas 5-HT does not. Thus, TS-induced activation of L29 could induce PTP at the L29-MN synapse, which could mask the immediate expression of inhibition. This interpretation is consistent with the results of Frost et al. (1988) and Fang and Clark (1996). Both groups observed enhancement of the L29-MN synapse after TS or tail nerve shock, but in both studies the L29 was strongly activated in response to TS, favoring the induction of PTP. To directly evaluate this possibility, we next examined the relationship between activity induced in the L29s during TS and inhibition induced by the same TS. 

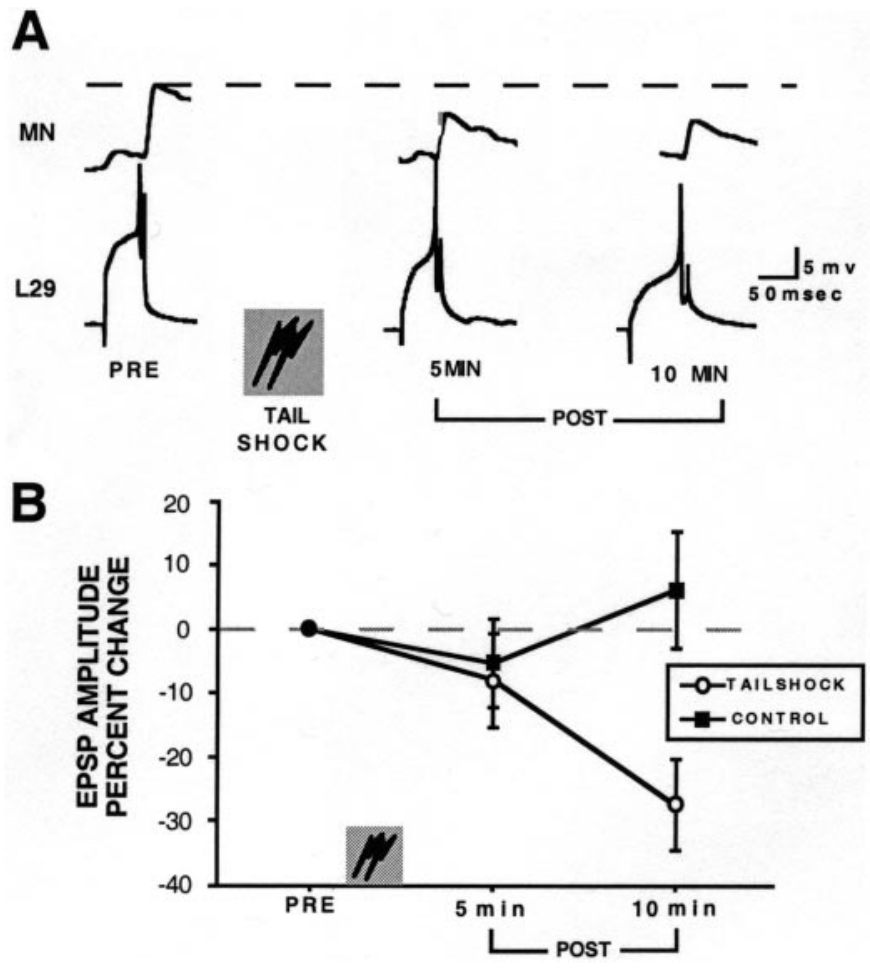

Figure 6. Tail shock (TS) inhibits the L29-MN EPSP. TS (45-60 mA, 1 $\mathrm{sec})$ was administered to the dorsal tail. Synaptic strength was measured before, $5 \mathrm{~min}$ after, and $10 \mathrm{~min}$ after TS. $A$, Simultaneous intracellular recordings from an L29 and a siphon MN. Tail shock symbol indicates when TS was administered. $B$, Summary data comparing the effect of TS on L29-MN synaptic strength. TS produced inhibition of the EPSP with maximum effect at $10 \mathrm{~min}$ after TS $(N=19$; mean baseline EPSP $=6.96$ $\mathrm{mV})$. Control preparations $(N=10$; mean baseline EPSP $=4.87 \mathrm{mV})$ not receiving TS showed no change. Average L29 firing frequency during $\mathrm{TS}=19.08 \mathrm{~Hz}, \mathrm{SEM} \pm 3.15$.

\section{The degree of L29 activation during TS determines the sign of synaptic plasticity}

The L29s vary in their responsiveness to TS. Hawkins and Schacher (1989) and Fischer and Carew (1995) both noted that L29s that were preferentially activated by either siphon or tail stimulation could be identified within the same preparation, suggesting that there are subsets of L29s that have varying degrees of responsiveness to tail stimulation. Given our previous results, we predicted that synaptic change should favor net facilitation for tail-responsive L29s, because their strong response to TS should produce a high level of intrinsic facilitation (PTP). In contrast, tail-unresponsive L29s, which are only weakly activated by TS, should show less facilitation, or even net depression, because the extrinsic inhibitory modulation (presumably mediated through 5-HT, although other modulators released by TS may also contribute; see Discussion) should outweigh the intrinsic facilitation. Furthermore, for comparable firing frequencies, any inhibitory effect of TS should be revealed as a reduction in PTP induced by TS activation compared with PTP produced by intracellular activation.

To test these predictions, we compared PTP induced by intracellular activation of L29 to that produced by activation of L29 in response to the first TS $(N=21)$. These experiments were supplemented by a subset of experiments in which L29s were only tetanized $(N=4)$ or only activated using TS $(N=4)$ to ensure that all frequencies of L29 activation were represented in the composite data set. As shown in Figure $7 A$, PTP induced by intracellular activation of L29 gave rise to a significant positive correlation between L29 firing frequency and change in synaptic strength at $10 \mathrm{sec}$ after tetanus $\left(R^{2}=0.38 ; t_{(23)}=4.79 ; p<0.05\right)$. Analysis of PTP induced by TS activation (Fig. $7 B$ ) also revealed a positive correlation between L29 firing frequency and change in synaptic strength $\left(R^{2}=0.25 ; t_{(23)}=2.76 ; p<0.05\right)$. However, consistent with our predictions, the slope of the regression line fit to the TS activation data were significantly reduced compared with that for the intracellular activation data $\left(t_{(46)}=4.59 ; p<\right.$ $0.05)$. This reduction in slope presumably reflects the competition of TS-induced inhibitory modulation with PTP.

A second, independent reflection of the inhibitory effects of TS was that, after TS, $\sim 25 \%$ of L29s that fired modestly in response to TS ( $\sim 25 \mathrm{~Hz}$ or less) showed net synaptic depression (Fig. $7 B$, shaded area). In contrast, after intracellular activation at comparable rates as induced by TS, there was no case in which an L29 showed synaptic depression, although many L29s $(N=12)$ were activated in the same lower range (Fig. 7A). Moreover, despite similar ranges in firing frequencies, 7 of 21 (33\%) of L29 driven intracellularly attained $300 \%$ enhancement, whereas no TSactivated L29s attained this level of PTP. Finally, considering all experiments, the average synaptic enhancement after TS (mean $=138 \%)$ was significantly less than after intracellular activation $\left(\right.$ mean $\left.=228 \% ; t_{(46)}=4.42 ; p<0.01\right)$. Collectively, these results indicate that, although TS is capable of activating L29 sufficiently to induce PTP, the facilitation is less than would occur with comparable intracellular activation. This effect is presumably attributable to the concurrent inhibitory effects of TS at the L29-MN synapse.

If the relative strength of intrinsic facilitation determines whether L29-MN synapses show facilitation or inhibition after TS, then it should be possible to control the direction of synaptic change by manipulating L29 activity during TS. To investigate this possibility, we assessed the responsiveness of the L29 to the first TS and measured the subsequent change in synaptic strength $10 \mathrm{sec}$ thereafter. During the second TS, the response of the L29 to the TS was manipulated, such that for those L29s that fired weakly ( $<10$ spikes; see Materials and Methods) during the first TS, we administered a tetanus $(20 \mathrm{~Hz}, 1 \mathrm{sec})$ during the second TS to increase L29 activity. For those L29s that fired strongly (>10 spikes) during the first TS, we injected strong (5-9 nA) hyperpolarizing current during the second TS to reduce L29 activity.

As shown in Figure $8 A$, for initially low responding L29s, tetanization during the second TS resulted in a significant increase in the amount of synaptic enhancement of the L29-MN EPSP after TS $\left(t_{(7)}=2.84 ; p<0.05\right)$. Conversely, hyperpolarization of initially high responding L29s significantly attenuated the facilitation exhibited in response to TS (Fig. $8 B)\left(t_{(5)}=3.82\right.$; $p<0.05)$. Figure 9 provides summary data comparing both types of experiments. The EPSP amplitude before and after TS is shown for both low- and high-responding L29s. In the lowresponding group (Fig. $9 A_{1}$ ) little net change is observed after the first TS. This is because this group includes the lower range of L29 responses, ranging from those that showed inhibition after TS, to those that show no change, to some that showed facilitation (Fig. $7 B$, lower firing frequencies). Nonetheless, during the second TS, tetanization induced a clear increase in EPSP amplitude. Conversely, in the high-responding group (Fig. $9 A_{2}$ ) facilitation is observed after the first TS and is clearly attenuated after hyperpolarization of the L29 during the second TS. A quantitative 
A

\section{INTRACELLULAR ACTIVATION}

Figure 7. TS-induced inhibition reduces L29 PTP. Comparison of PTP induced by intracellular activation $(A)$ with $\mathrm{PTP}$ induced by TS activation $(B)$. After a baseline EPSP measurement, PTP was induced by intracellular activation of an L29 at varying frequencies in different experiments for $1 \mathrm{sec}$ and tested $10 \mathrm{sec}$ after stimulation. Similarly, after a baseline EPSP measurement, a TS (45-60 mA, $1 \mathrm{sec})$ was applied to the dorsal surface of the tail, and the EPSP was tested $10 \mathrm{sec}$ after shock ( filled triangles; $N=21$ ). In a subset of experiments (asterisks), L29s were only tetanized $(N=4)$ or activated by TS $(N=4)$. $A$, Scatterplot depicting percentage of change in EPSP amplitude as a function of L29 firing frequency when the L29 was activated intracellularly. B, Scatterplot depicting percentage of change in EPSP amplitude as a function of L29 firing frequency when the L29 was activated by TS. In each graph, line represents best-fit line. Shaded area indicates frequencies over which synaptic inhibition was observed after L29 activation by TS.
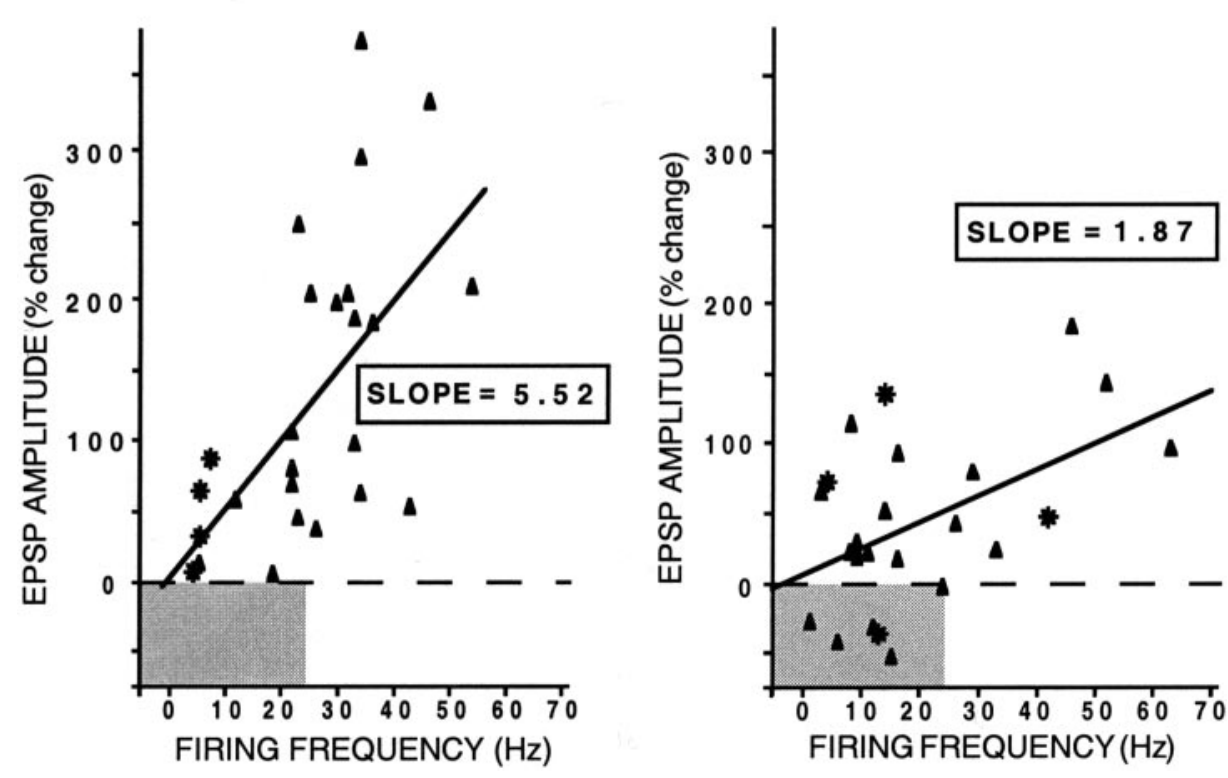

$\mathbf{A}$

$\mathbf{B}$

B

\section{TAILSHOCK ACTIVATION}

Figure 8. L29 activation during TS determines net synaptic change. After a baseline EPSP measurement, a TS was administered and an EPSP test was taken $10 \mathrm{sec}$ after shock. The procedure was repeated 10 min later with the addition of an intracellular activation (20 $\mathrm{Hz}, 1 \mathrm{sec}$ ) or hyperpolarization (5-9 nA) of the L29 applied during the second TS. A, Recordings from a siphon $\mathrm{MN}$ and a low-responding L29 interneuron during TS. The response of the L29 during the TS event is shown in the inset. Top, After the first TS, the EPSP was reduced below baseline (dashed lines). Bottom, During the second TS, the L29 was activated intracellularly, as indicated in the inset. After the second TS, the EPSP was now increased above baseline. $B$, Recordings of a siphon MN and a high-responding L29 interneuron during TS. Top, After the first TS, the EPSP was elevated above baseline. Bottom, The response of the L29 was reduced although hyperpolarization during the second TS, as indicated in the inset. After the second TS, the EPSP was now decreased below baseline.
FIRST TAILSHOCK
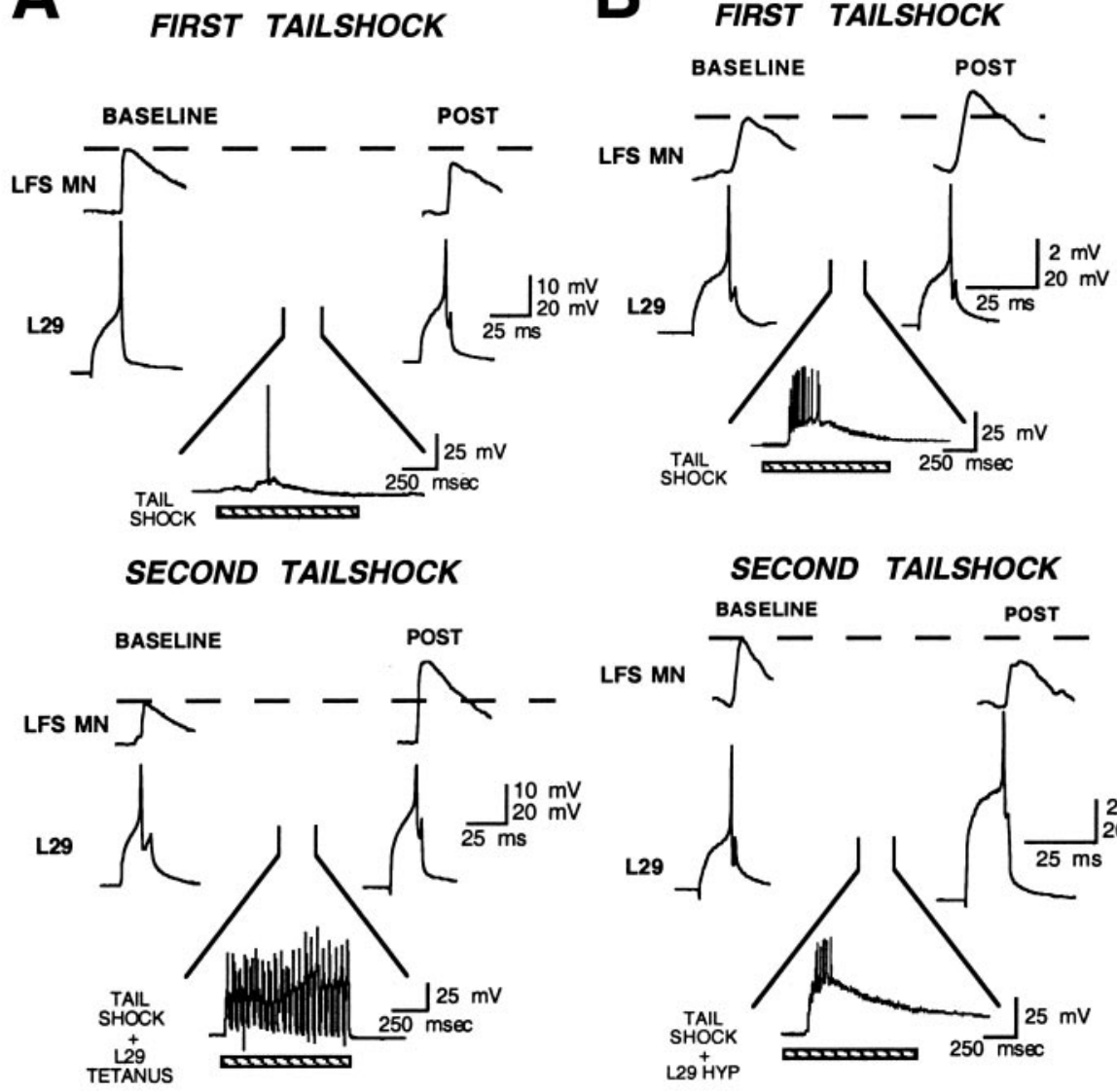

comparison of these effects is shown in Figure 9B, which reveals a significant difference between the groups in synaptic change after the second TS $\left(t_{(12)}=4.10 ; p<0.05\right)$. Because of the strength with which TS activates tail-responsive L29s, we found that hyperpolarization of the L29 during the second TS was usually unable to completely prevent L29 spiking (average reduction $=\sim 30 \%$ ), thus the profiles for facilitation and depression are not symmetrical. 
A

LOW RESPONDING L29s

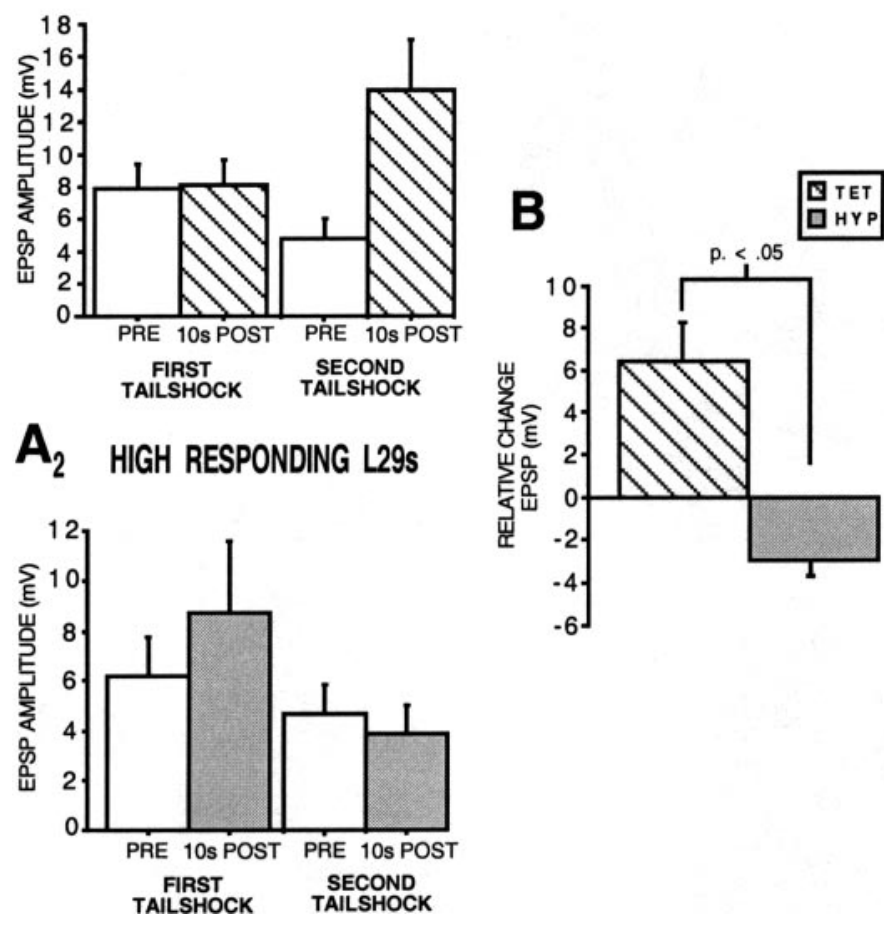

Figure 9. Summary data. $A_{1}$, EPSP amplitude before and $10 \mathrm{sec}$ after two separate TSs for low-responding L29s are shown $(N=8)$. During the second TS, the L29s were tetanized at $20 \mathrm{~Hz} . A_{2}$, EPSP amplitude before and $10 \mathrm{sec}$ after two separate TSs for high-responding L29s are shown $(N=6)$. During the second TS, the L29s were hyperpolarized to reduce or prevent spiking. $B$, Quantitative comparison of experiments in which L29 responsiveness to TS was manipulated. Activation of unresponsive L29s during TS resulted in a net increase in L29-MN synaptic strength, whereas hyperpolarization of responsive L29s during TS resulted in a net decrease in synaptic strength.

Our prediction that strongly activated L29s during TS should show net facilitation whereas weakly activated L29s should show net depression is based on the assumption that TS-induced inhibition is relatively uniform for all L29s. If this were not the case, some of the differences in net facilitation we observe (Figs. 8, 9) may not be caused by differences in the degree of intrinsic activation among subsets of L29s, but rather to differences in the magnitude of inhibition they receive from TS. To directly address this question, we compared the magnitude of 5-HT-induced inhibition of high and low responding L29s $10 \mathrm{~min}$ after TS, a time point when PTP has diminished (Fig. 10A). We found no difference in the amount of TS-induced inhibition exerted on the two subpopulations of L29s (Fig. 10B) $\left(t_{(18)}=-0.539 ; N S\right)$. Thus, TS appears to inhibit tail-responsive and tail-unresponsive L29s with equal effectiveness. Taken together, these experiments show that TS is capable of uniformly depressing the L29-MN synapses, but that the responsiveness of the L29 to TS (and the resulting degree of intrinsic facilitation) plays a pivotal role in determining the ultimate sign of synaptic plasticity.

\section{DISCUSSION}

In the present study, we investigated how intrinsic facilitation and extrinsic inhibitory modulation combine in the induction of synaptic change at an excitatory synapse within the SWR circuit of Aplysia. We examined the identified excitatory synapse between a
A

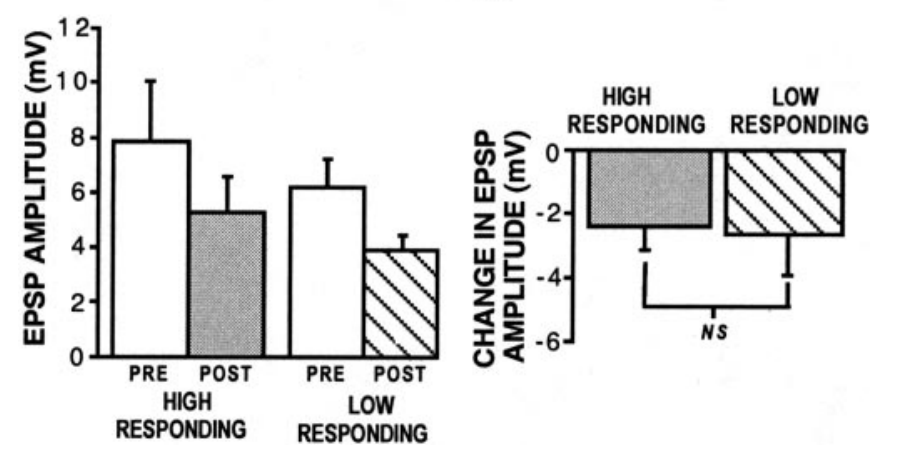

Figure 10. TS exerts uniform inhibition on high-responding and lowresponding L29s. The inhibitory effect of TS on high-responding and low-responding L29s was assessed at 10 min after TS, a time when PTP has returned to baseline. $A$, Summary data from 19 experiments showing a reduction in EPSP amplitude 10 min after TS for both high-responding (left) and low-responding (right) L29 synapses. B, A quantitative comparison of the change in EPSP amplitude in both conditions shows that there is no difference in the amount of inhibition, expressed as change in EPSP amplitude $10 \mathrm{~min}$ after TS, for high- and low-responding L29 synapses.

class of interneurons, the L29s, and siphon MNs and found that this synapse exhibits a clear form of intrinsic facilitation, PTP: brief tetanus of L29 results in a significant enhancement of the L29-MN synapse that lasts $\sim 10 \mathrm{~min}$. In addition, we found that this same synapse shows marked inhibitory modulation: a brief (2 min) exposure to 5-HT depresses the L29-MN synapse, an effect that is maximal immediately after 5 -HT treatment. These opposing forms of plasticity can overlap. Thus, the magnitude of both baseline synaptic transmission and PTP at the L29-MN synapse is reduced $30 \mathrm{sec}$ after 5-HT application. Similarly, the complex EPSP measured in the MN during L29 activation is also reduced by 5 -HT. In parallel experiments, we found that TS has a comparable inhibitory effect on the L29-MN EPSP. The effect of TS could be observed as both a general depression of L29-MN synaptic transmission observed at $10 \mathrm{~min}$ after TS and as a reduction in PTP induced by TS activation of L29. Tail and body wall shocks are known to evoke the release of 5-HT in Aplysia (Mackey et al., 1989; Fitzgerald and Carew, 1991; Fischer et al., 1997; Levenson et al., 1999; Marinesco and Carew, 2000). Moreover, considerable evidence supports the view that TS gives rise to 5-HT-mediated plasticity in both siphon and tail withdrawal systems (Castellucci et al., 1970; Glanzman et al., 1989; Fitzgerald and Carew, 1991; Mercer et al., 1991; Fischer et al., 1997). These results strongly suggest that the inhibitory effect of TS are mediated, at least in part, by 5-HT. Finally, we found that we could influence the sign and magnitude of TS-induced plasticity at the L29-MN synapse by directly manipulating L29 activity during TS. When we tetanized normally tail-unresponsive L29s during TS, we observed a significant enhancement of synaptic strength. When we hyperpolarized tail-responsive L29s during TS, we reduced or abolished the synaptic enhancement observed after TS.

Our results shed light on an interesting paradox that can be seen in the study of L29 modulation. On the one hand, TS can evoke strong activation of the L29s, thereby inducing intrinsic facilitation at the L29-MN synapses. Both Frost et al.(1988) and Fang and Clark (1996) previously reported an enhancement of the L29-MN synapse after TS and tail nerve shock, respectively, and attributed the synaptic change to PTP. On the other hand, TS (and 5-HT) also induces inhibitory modulation at the same set of 
HIGH ACTIVITY L29

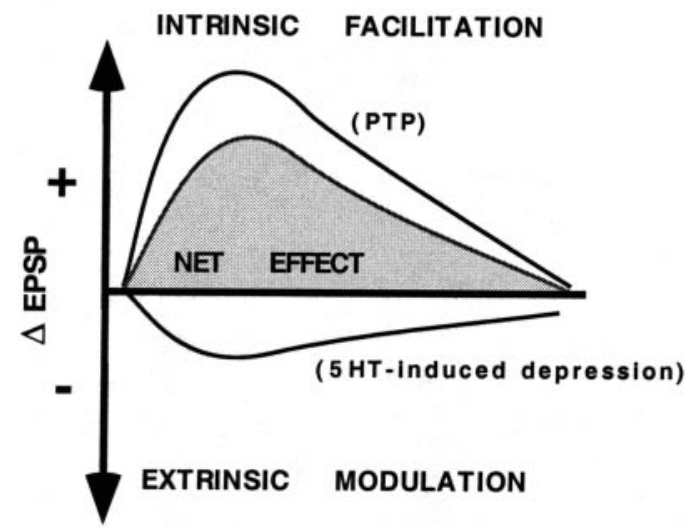

LOW ACTIVITY L29

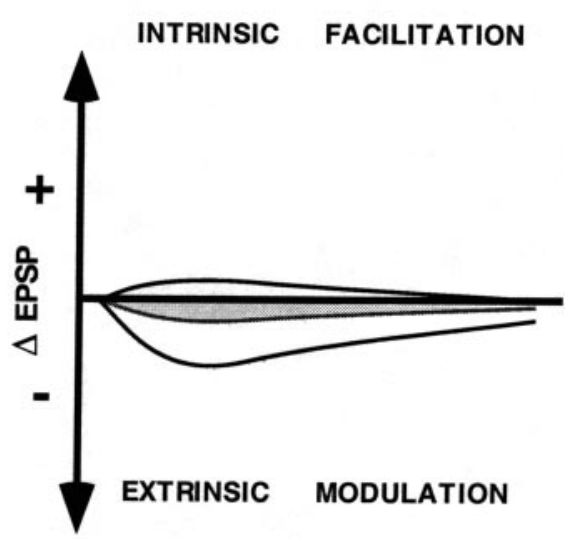

Figure 11. A model of dual modulation of L29 by activity and by 5-HT during TS. Intrinsic facilitation $(P T P)$ and extrinsic modulation (5-HT-induced inhibition) serve to enhance and reduce the EPSP amplitude, respectively. The net effect on EPSP amplitude is a sum of these two opposing processes. Left, For HIGH ACTIVITY L29s, intrinsic facilitation offsets extrinsic inhibitory modulation, giving rise to net synaptic enhancement (shaded area). Right, For LOW ACTIVITY L29s, intrinsic facilitation is weak compared with extrinsic inhibitory modulation, with a net effect of no change or a reduction in synaptic strength (shaded area). synapses and in the SWR circuit (Fitzgerald and Carew, 1991; Trudeau and Castellucci, 1993; Illich et al., 1994; Wright and Carew, 1995). Thus, the question arises: which of these opposite effects prevail after TS activation of the SWR circuit? Our results show that the degree of L29 activity is a key determinant of the sign and the magnitude of plasticity induced at the L29-MN synapse by TS. A general model illustrating this point is shown in Figure 11. L29 PTP and 5-HT-inhibition can overlap in time: when L29 activity is high, PTP outweighs inhibitory modulation, but when L29 activity is low, inhibitory modulation predominates.

\section{Modulation of synaptic plasticity within the SWR neural circuit}

Some of the effects of 5-HT we report here are similar to the effects of 5-HT reported by Fischer et al. (1997), who examined another identified synapse within the SWR network, that between the inhibitory L30 interneurons and the L29s. They also observed an inhibitory effect of 5-HT and TS on both basal transmission (see also, Frost et al., 1988) and PTP. However, 5-HT had no effect on frequency facilitation (FF), a form of intrinsic enhancement expressed during tetanus (Zucker, 1989; Fisher et al., 1997; Fischer et al., 1997). Thus, at the L30-L29 synapse, 5-HT and TS differentially modulated two forms of intrinsic plasticity (reducing PTP but leaving FF intact), suggesting that TS-induced release of 5-HT affected a process underlying PTP. In contrast, our results show that 5-HT has a more generalized effect on L29 plasticity. Consistent with this view, when we normalized the PTP data to account for the reduction in baseline synaptic transmission, we found that it was similar before and after 5-HT. Thus, it appears that 5-HT-induced reduction of PTP at the L29-MN synapse is attributable primarily to the effect of 5-HT of reducing baseline synaptic transmission. Regardless of the underlying mechanism, the functional consequence of 5-HT modulation is a reduction in both baseline and facilitated synaptic input from the L29 onto the MN.

\section{Contribution of L29 modulation to TS-induced changes in the SWR}

TS-induced sensitization is a well studied form of learning in the SWR. Sensitization is typically measured as an increase in the strength of the SWR after TS. However, before the onset of TS-induced sensitization there is a brief period of response inhibition (Mackey et al., 1987; Marcus et al., 1988; Fitzgerald and Carew, 1991). Moreover, during this period of inhibition there is a change in response topography such that head-directed constrictions of the siphon are inhibited and a tail-directed flaring of the siphon emerges (Erickson and Walters, 1988; Illich et al., 1994). The L29s have generally been thought to contribute to behavioral sensitization: (1) via modulatory (facilitatory) actions on siphon SNs (Hawkins et al., 1981b) and (2) via intrinsic enhancement of their synaptic input onto siphon MNs (Cleary et al., 1995; Frost and Kandel, 1995). Our results, taken with previous findings (Mackey et al., 1987; Marcus et al., 1988; Fitzgerald and Carew, 1991; Wright et al., 1991; Trudeau and Castellucci, 1993) raise the possibility that the 5-HT-induced inhibitory modulation of the L29-MN synapse we observe may contribute to TS-induced inhibition in the SWR.

\section{Information gating in neural networks}

Our findings address a general issue concerning the manner in which modulation of information processing can occur within a neural network. The differential effect of TS on tail-responsive and tail-unresponsive L29s illustrates how a general modulatory signal is still capable of permitting cell-specific effects by acting in parallel with processes affecting intrinsic neuronal properties. Similar forms of network-level modulation have been found in neural circuits responsible for generating rhythmic motor patterns, such as stomatogastric ganglion (STG; Harris-Warrick et al., 1992), locust flight systems (Pierson and Ramirez, 1992), and vertebrate spinal cord (Barbeau and Rossignol, 1991). In Aplysia, TS-induced inhibition (presumably acting, at least in part, through the release of 5-HT) appears to be exerted uniformly on all L29s within the SWR circuit. However, L29 activity, which can counteract the inhibitory effect, can be specific, dictated by the individual receptive fields of the L29s and their intrinsic circuit connectivity.

Such a functional organization, which combines network inhibition and cell-specific facilitation, could be used to increase the signal value of a specific stimulus in a complex neural network. Moreover, given the differences in L29 receptive fields, the functional organization of general modulatory inhibition coupled with cell-specific facilitation gives rise to a modulation-derived form of "center-surround" information processing. Center-surround organization of sensory receptive fields, where regions peripheral to a central excitatory region are inhibitory ("on-center" organization), is a hallmark of sensory processing (Martin, 1991). Centersurround antagonism has been most extensively studies in the 
visual system, in particular within the retina (Kuffler, 1953; Sterling, 1998), where the mechanism underlying this organization can be traced to the actions of inhibitory input from interneurons activated by neighboring regions of the visual field. Thus, in the vertebrate visual system, the pattern of connectivity is responsible for the surround inhibition. Our data show that L29s activated strongly by TS (the "center") are facilitated, whereas L29 weakly activated by TS (the "surround") are inhibited. For several minutes after TS, sensory input mediated through L29s in the center region will maintain high throughput, whereas input mediated by L29s outside the center will be attenuated by inhibition. For this model to be effective, different L29s would have to have differentially weighted synaptic output onto their follower cells. We are currently exploring this important question. If such centersurround information processing does occur, it would be derived not from the pattern of connectivity (as is the case in the retina), but rather from the pattern of modulation in the SWR circuitry. This general organizational feature, in which restricted intrinsic facilitation is superimposed on a modulatory background of general inhibition, can provide a mechanism for enhanced contrast for information processing within a neural network.

\section{REFERENCES}

Armitage BA, Siegelbaum SA (1998) Presynaptic induction and expression of homosynaptic depression at Aplysia sensorimotor neuron synapses. J Neurosci 18:8770-8779.

Barbeau H, Rossignol S (1991) Initiation and modulation of the locomotor pattern in the adult chronic spinal cat by noradrenergic, serotonergic, and dopaminergic drugs. Brain Res 546:250-260.

Bear MF (1999) Homosynaptic long-term depression: a mechanism for memory? Proc Natl Acad Sci USA 96:9457-9458.

Belkin KJ, Abrams TW (1998) The effect of the neuropeptide FMRFamide on Aplysia californica siphon motoneurons involves multiple ionic currents that vary seasonally. J Exp Biol 201:2225-2234.

Bristol AS, Fischer TM, Carew TJ (1998) Characterization and modulation of activity-dependent plasticity at the L29-MN synapse in Aplysia. Soc Neurosci Abstr 24:702.

Bristol AS, Fischer TF, Carew TJ (1999) Interactions between intrinsic and extrinsic modulation determines the sign of plasticity induced by tailshock at the L29-MN synapse in Aplysia. Soc Neurosci Abstr 25:863.

Buonomano DV, Merzenich MM (1998) Net interaction between different forms of short-term synaptic plasticity and slow-IPSPs in the hippocampus and auditory cortex. J Neurophysiol 80:1765-1774.

Byrne JH, Kandel ER (1996) Presynaptic facilitation revisited: State and time dependence. J Neurosci 16:425-435.

Carew TJ, Walters ET, Kandel ER (1981) Classical conditioning in a simple withdrawal reflex in Aplysia californica. J Neurosci 1:1426-1437.

Castellucci VF, Kandel ER (1976) Presynaptic facilitation as a mechanism for behavioural sensitization in Aplysia. Science 194:1176-1178.

Castellucci VF, Pinsker H, Kupfermann I, Kandel ER (1970) Neuronal mechanisms of habituation and dishabituation of the gill-withdrawal reflex in Aplysia. Science 175:451-454.

Cleary LJ, Byrne JH, Frost WN (1995) Role of interneurons in defensive reflexes in Aplysia. Learn Mem 2:133-151.

Corradetti R, Ballerini L, Pugliese AM, Pepeu G (1992) Serotonin blocks the long-term potentiation induced by primed burst stimulation in the CA1 region of rat hippocampal slices. Neuroscience 46:511-518.

Emptage NJ, Carew TJ (1993) Long-term synaptic facilitation in the absence of short-term facilitation in Aplysia neurons. Science 262:253-256.

Erickson M, Walters E (1988) Differential expression of pseudoconditioning and sensitization by siphon responses in Aplysia: novel response selection after training. J Neurosci 8:3000-3010.

Fang X, Clark GA (1996) Differential responses of Aplysia siphon motor neurons and interneurons to tail and mantle stimuli: implications for behavioral response specificity. J Neurophysiol 76:3895-3909.

Fischer TM, Carew TJ (1995) Cutaneous activation of the inhibitory L30 interneurons provides a mechanism for regulating adaptive gain control in the siphon withdrawal reflex in Aplysia. J Neurosci 15:762-773.

Fischer TM, Blazis DEJ, Priver N, Carew TJ (1997) Metaplasticity at identified inhibitory synapses in Aplysia. Nature 389:860-865.

Fisher SA, Fischer TM, Carew TJ (1997) Multiple overlapping processes underlying short-term synaptic enhancement. Trends Neurosci 20:170-177.

Fitzgerald K, Carew TJ (1991) Serotonin mimics tail shock in producing transient inhibition in the siphon withdrawal reflex of Aplysia. J Neurosci 11:2510-2518.

Frost WN, Kandel ER (1995) Structure of the network mediating siphon-elicited siphon withdrawal in Aplysia. J Neurophysiol 73:2413-2427.

Frost WN, Clark GA, Kandel ER (1988) Parallel processing of shortterm memory for sensitization in Aplysia. J Neurobiol 19:297-334.

Glanzman DL, Mackey SL, Hawkins RD, Dyke AM, Lloyd PE, Kandel ER (1989) Depletion of serotonin in the nervous system of Aplysia reduces the behavioral enhancement of gill withdrawal as well as the heterosynaptic facilitation produced by tail shock. J Neurosci 9:4200-4213.

Harris-Warrick RM, Marder E, Selverston AI, Moulins M (1992) Dynamic biological networks: the stomatogastric nervous system. Cambridge, MA: MIT.

Hawkins RD (1989) Localization of potential serotonergic facilitator neurons in Aplysia by glioxylic acid histofluorescence combined with retrograde fluorescent labeling. J Neurosci 9:4214-4226.

Hawkins RD, Schacher S (1989) Identified facilitator neurons L29 and L28 are excited by cutaneous stimuli used in dishabituation, sensitization, and classical conditioning of Aplysia. J Neurosci 9:4236-4245.

Hawkins RD, Castellucci VF, Kandel ER (1981a) Interneurons involved in mediation and modulation of gill-withdrawal reflex in Aplysia. I. Identification and characterization. J Neurophysiol 45:304-314.

Hawkins RD, Castellucci VF, Kandel ER (1981b) Interneurons involved in mediation and modulation of gill-withdrawal reflex in Aplysia. II. Identified neurons produce heterosynaptic facilitation contributing to behavioral sensitization. J Neurophysiol 45:315-326.

Hawkins RD, Abrams TW, Carew TJ, Kandel ER (1983) A cellular mechanism of classical conditioning in Aplysia: activity-dependent amplification of presynaptic facilitation. Science 219:400-405.

Hawkins RD, Cohen TE, Greene W, Kandel ER (1998) Relationships between dishabituation, sensitization, and inhibition of the gill- and siphon-withdrawal reflex in Aplysia californica: effects of response measure, test time, and training stimulus. Behav Neurosci 112:24-38.

Hickie C, Walters ET (1995) Motor neuronal control of tail-directed and head-directed siphon responses in Aplysia californica. J Neurophysiol 74:307-321.

Howell DC (1997) Statistical methods in psychology, Ed 4. Belmont, CA: Duxsbury.

Illich PA, Joynes RL, Walters ET (1994) Response-specific inhibition during general facilitation of defensive responses in Aplysia. Behav Neurosci 108:614-623.

Katz PS, Frost WN (1995) Intrinsic neuromodulation in the Tritonia swim CPG: the serotonergic dorsal swim interneurons act presynaptically to enhance transmitter release from interneuron C2. J Neurosci 15:6035-6045.

Kim JJ, Yoon KS (1998) Stress: metaplastic effects in the hippocampus. Trends Neurosci 21:505-509.

Kistler HB, Hawkins RD, Koester J, Steinbusch HWM, Kandel ER, Schwartz JH (1985) Distribution of serotonin-immunoreactive cell bodies and processes in the abdominal ganglion of mature Aplysia. J Neurosci 5:72-80.

Krasne FB (1978) Extrinsic control of intrinsic neuronal plasticity: An hypothesis from work on simple systems. Brain Res 140:197-216.

Kuffler SW (1953) Discharge patterns and functional organization of mammalian retina. J Neurophysiol 16:37-68.

Levenson J, Byrne J, Eskin A (1999) Levels of serotonin in the hemolymph of Aplysia are modulated by light/dark cycles and sensitization training. J Neurosci 19:8094-8103.

Longley RD, Longley AJ (1986) Serotonin immunoreactivity of neurons in the gastropod Aplysia californica. J Neurobiol 17:339-358.

Mackey SL, Glanzman DL, Small SA, Dyke AM, Kandel ER, Hawkins RD (1987) Tail shock produces inhibition as well as sensitization of the siphon withdrawal reflex of Aplysia: possible behavioral role for presynaptic inhibition mediated by the peptide Phe-Met-Arg-Phe- $\mathrm{NH}_{2}$. Proc Natl Acad Sci USA 84:8730-8734.

Mackey SL, Kandel ER, Hawkins RD (1989) Identified serotonergic neurons LCB1 and RCB1 in the cerebral ganglia of Aplysia produce presynaptic facilitation of siphon sensory neurons. J Neurosci 9:4227-4235.

Malenka RC, Nicoll RA (1999) Long-term potentiation-a decade of progress? Science 285:1870-1874.

Marcus EA, Nolen TG, Rankin CH, Carew TJ (1988) Behavioral dissociation of dishabituation, sensitization, and inhibition of Aplysia. Science 241:210-213.

Marinesco S, Carew TJ (2000) Electrochemical detection of serotonin release induced by tail-nerve shock in Aplysia. Soc Neurosci Abstr 26:1523.

Martin JH (1991) Coding and processing of sensory information. In: Principles of neural science, Ed 3 (Kandel ER, Schwartz JH, Jessell TM, eds), pp 329-340. Norwalk, CT: Appleton \& Lange. 
Mercer AR, Emptage NJ, Carew TJ (1991) Pharmacological dissociation of modulatory effects of serotonin in Aplysia sensory neurons. Science 254:1811-1813.

Montarolo PG, Kandel ER, Schacher S (1988) Long-term heterosynaptic inhibition in Aplysia. Nature 333:171-174.

Pierson KG, Ramirez JM (1992) Parallels with other invertebrate and vertebrate motor systems. In: Dynamic biological networks: the stomatogastric nervous system (Harris-Warrick RM, Marder E, Selverston AI, Moulins M, eds), pp 263-282. Cambridge, MA: MIT.

Ryall RW (1978) Presynaptic inhibition. Trends Neurosci 1:164-166.

Sterling P (1998) Retina. In: The synaptic organization of the brain, Ed 4 (Shepherd GM, ed), pp 205-254. New York: Oxford UP.

Terman GW, Wagner JJ, Chavkin C (1994) Kappa opioids inhibit induction of long-term potentiation in the dentate gyrus of the guinea pig hippocampus. J Neurosci 14:4740-4747.
Trudeau LE, Castellucci VF (1993) Sensitization of the gill and siphon withdrawal reflex of Aplysia: multiple sites of change in the neuronal network. J Neurophysiol 70:1210-1220.

Villani F, Johnston D (1993) Serotonin inhibits induction of long-term potentiation at commissural synapses in hippocampus. Brain Res 606:304-308.

Walters ET, Byrne JH (1983) Associative conditioning of single sensory neurons suggests a cellular mechanism for learning. Science 219:405-408.

Wright WG, Carew TJ (1995) A single identified interneuron gates tailshock induced inhibition in the siphon withdrawal reflex in Aplysia. J Neurosci 15:790-797.

Wright WG, Marcus EA, Carew TJ (1991) A cellular analysis of inhibition in the siphon withdrawal reflex of Aplysia. J Neurosci 11:2498-2509.

Zucker RS (1989) Short-term synaptic plasticity. Annu Rev Neurosci 12:13-31. 